\title{
ESTUDO SOBRE TEORIA TRANSCULTURAL DE LEININGER
}

\author{
Dulce Maria Rosa Gualda* \\ Luiza Akiko Komura Hoga*
}

GUALDA, D.M.R.; HOGA, L.A.K. Estudo sobre teoria transcultural de Leininger. Rev. Esc. Enf. USP, v. 26, n. 1, p. 75-86, mar. 1992.

Este artigo aborda a Teoria Transcultural do Cuidado de Leininger. Faz um breve histórico de sua evolução, apresenta definiçóes e alguns pressuspostos e sumariza considerações a respeito do "Sunrise" - Modelo Teórico Conceitual da Diversidade e Universalidade Transcultural do Cuidado, desenvolvido e utilizado pela autora desde 1965.

UNITERMOS: Enfermagem transcultural. Teoria de Enfermagem

\section{INTRODUÇĀO}

O desenvolvimento do conhecimento científico e humanístico da enfermagem representa uma conquista da profissão e é grandemente devido à curiosidade intelectual e ao esforço persistente de enfermeiros teoristas e pesquisadores.

Teorias de enfermagem são guias extremamente importantes e auxiliam os profissionais a criar, testar e aperfeiçoar um corpo específico de conhecimento, bem como a facilitar a compreensão das ações, dos objetivos e dos propósitos da prática, da educação e da pesquisa. Assim sendo, o foco principal das teorias tem sido a definição da essência da enfermagem e de suas principais características.

Inserido nesta perspectiva, tem havido, nos últimos trinta anos, um esforço no sentido de ampliação e consolidação da área da enfermagem transcultural. Segundo relato de LEININGER (1986), a evolução histórica desta área foi iniciada na década de 1950, nos Estados Unidos da América (EUA). Houve muita dificuldade para sua aceitação pelas enfermeiras, pois o conhecimento cultural destas era deficiente; estavam mais voltadas para a busca da identidade e da competência técnica, com interesse virtualmente ausente nos aspectos culturais relacionados à profissão.

Inicialmente as enfermeiras interessadas na área buscaram seu aprimoramento nos programas de pós-graduação em antropologia, onde procuraram aumentar tanto o conhecimento teórico como o de metodologia de pesquisa.

\footnotetext{
- Enfermeira. Mestre em Enfermagem. Assistentes do Departamento de Enfermagem Materno-Infantil da Escola de Enfermagem da USP.
} 
O próximo passo foi o de conciliar os objetivos da antropologia e os da enfermagem. LEININGER, orientada por MEAD, foi uma das responsáveis por esta iniciação, obtida por meio da implantação de dois programas de pós-graduação de 1965 a $1967 \mathrm{e}$, simultaneamente, pelo desenvolvimento da "Teoria Transcultural da Enfermagem' ' e da metodologia específica de pesquisa relativa à enfermagem transcultural.

Uma das primeiras manifestações da importância do enfoque antropológico na prática de enfermagem, encontrada na literatura desta profissão, foi escrita por MEAD (1956), quando ressaltou a importância do conhecimento das diferenças de padrōes de comportamento de pessoas com bagagem cultural diversificada; afirmava que as enfermeiras consideravam-se preparadas para contemplar o aspecto cultural, mas que na verdade isto não ocorria. Considerava a autora que, para se ter acesso à bagagem cultural tanto do paciente e familiares, como de outras enfermeiras ou qualquer membro da equipe profissional, seria necessário ter-se alguma experiência com tipos de diferenças culturais, além de idéia clara daquilo que se procurava; criticou os órgãos formadores de enfermeiros pela ausência de abordagem destes aspectos no currículo do curso de graduação, por julgar que a compreensão dos padrões de vida é essencial para uma boa assistência de enfermagem.

Em 1974 foi iniciada uma série de eventos anuais, denominados "National Transcultural Nursing Conferences", que iriam tornar-se uma fonte de referência importante da prática, ensino e pesquisa em enfermagem transcultural.

Foi no período de 1975 a 1983 que houve um maior incremento de interesse pela enfermagem trancultural, passando a ser valorizadas as enfermeiras com preparo antropológico e em métodos de pesquisa de campo. Mesmo assim, o número dessas enfermeiras era insuficiente para a demanda dos programas de pósgraduação em enfermagem. Nesta ocasião foram criados dois programas de doutorado na Universidade de Utah e Wayne State University e $20 \%$ das escolas de enfermagem reconhecidas pela "National League for Nursing" ofereceram cursos de graduação com enfoque cultural. Só então algumas profissionais brasileiras tiveram contato com a enfermagem transcultural nos programas existentes nos EUA. Esta fase foi marcada por um aumento substancial de publicações livros e artigos em periódicos americanos abordando cultura e enfermagem.

A partir de 1983 houve uma expansão significativa no panorama internacional da enfermagem transcultural, e a consolidação da importância do enfoque cultural na enfermagem, de pesquisas realizadas no país e em grupos minoritários dos EUA.

A enfermagem transcultural, para LEININGER (1978), tem como foco o estudo da análise comparativa de diferentes culturas ou subculturas, no que diz respeito ao comportamento relativo ao cuidado em geral, ao cuidado de enfermagem, assim como aos valores, crenças e padrões de comportamento relacionados a saúde e doença. O objetivo é desenvolver um corpo de conhecimento científico e humanizado, capaz de possibilitar a prática do cuidado de enfermagem universal e culturalmente específico; afirma, ainda, que o objetivo da enfermagem transcultural vai além da apreciação de culturas diferentes, mas de tomar o conhecimento e a prática profissional culturalmente embasada, conceituada, planejada e operacionalizada. 
A mesma autora define sua teoria como sendo o conjunto inter-relacionado de conceitos e hipóteses de enfermagem fundamentados na necessidades culturais de indivíduos e grupos; estes conceitos incluem manifestações de comportamento relativos ao cuidado, crenças e valores, com a finalidade de que seja prestado um cuidado de enfermagem efetivo e satisfatório. Se aqueles que praticam a enfermagem não considerarem os aspectos culturais da necessidade humana, suas ações poderão ser ineficazes, e trazer conseqüências desfavoráveis para os assistidos.

\section{TERMOS BÁSICOS DA ENFERMAGEM TRANSCULTURAL}

$\mathrm{Na}$ discussão da teoria transcultural alguns termos são relevantes e precisam ser conceituados. A seguir apresentamos esta conceituação segundo LEININGER (1985 a)

CULTURA - Valores, crenças, normas de comportamento e práticas relativas ao estilo de vida, aprendidos, compartilhados e transmitidos por um grupo específico, que orientam o pensamento, as decisões e as ações dos elementos pertencentes ao grupo.

CUIDADO - Fenômeno de assistência, apoio ou facilitação a outro indivíduo ou grupo com necessidades antecipadas ou evidentes, com a finalidade de melhorar a condição humana ou o estilo de vida.

VALORES CULTURAIS - Forças diretivas que comandam ou dão significado ao pensamento, às decisões e às ações de indivíduos de um determinado grupo, que se mantém numa mesma cultura por certo período de tempo.

VALOR CULTURAL DO CUIDADO - Modo de agir ou pensar mais desejável ou preferido, que é mantido por um período de tempo e que direciona as ações e decisões relativas ao cuidado.

DIVERSIDADE CULTURAL DO CUIDADO - Variabilidade do significado dos padrões, valores ou símbolos que envolvem o cuidado.

UNIVERSALIDADE CULTURAL DO CUIDADO - Uniformidade cultural do significado dos padrões, valores ou símbolos que envolvem o cuidado.

VISÃO DE MUNDO - Modo como os indivíduos percebem seu mundo ou universo, e nele inserem sua perspectiva de vida.

ESTRUTURA SOCIAL - Processo dinâmico e natureza interdependente de diferentes elementos estruturais ou organizacionais da sociedade, e o modo como esses elementos interatuam e funcionam. Incluem os sistemas religioso, familiar, político, ecônomico, educacional, tecnológico e cultural, delimitados pelo contexto linguístico e ambiental.

CONTEXTO DE CUIDADO E CURA E SISTEMA DE SAÚDE - A totalidade de experiências ou o ambiente no qual o indivíduo se encontra, em situações diversas, incluindo os sistemas e organizações nos quais as pessoas procuram cuidar e tratar de outras. Dentro do sistema de saúde podem ser caracterizados:

* Sistema Popular - Sistema local que oferece serviços às pessoas com base nas práticas tradicionais de cuidado ou cura. 
* Sistema Profissional - Serviços de cuidado e tratamento organizados e interdependentes, oferecidos por profissiona is formalmente preparados.

LEININGER (1978) acredita que a teoria transcultural seja capaz de predizer e explicar os padrōes de cuidado humano das diversas culturas, bem como possibilitar a identificação de valores, crenças e práticas populares dos profissionais e da enfermagem. Acredita que, por meio deste conhecimento, as decisões e as ações de enfermagem podem tornar-se congruentes e benéficas para aqueles que são assistidos. $\mathrm{Na}$ análise da abordagem de enfermagem, distingue três formas de atuação:

* Preservação Cultural do Cuidado - Fenômeno culturalmente embasado, de assistir, facilitar ou capacitar o indivíduo, que o auxilia a preservar ou manter hábitos favoráveis de cuidado e de saúde.

* Acomodação Cultural do Cuidado - Ato, culturalmente embasado, de assistir, facilitar ou capacitar, que revela formas de adaptação, negociação ou ajustamento dos hábitos de saúde e de vida dos indivíduos ou clientes.

* Reestruturação Cultural do Cuidado - Modelos reconstruídos ou alterados para auxiliar o cliente a mudar os padrōes de saúde ou de vida, de forma a tornar significativo ou congruente para ele próprio.

\section{PRESSUPOSTOS BÁSICOS DA ENFERMAGEM TRANSCULTURAL}

Com o objetivo de aprofundar o conhecimento da natureza e das características da enfermagem transcultural, os pressupostos que seguem precisam se aclarados.

* A enfermagem é um fenômeno essencialmente transcultural que envolve o contexto e o processo de ajuda a indivíduos de diferentes orientações culturais ou de estilos de vida específicos dentro de determinada cultura.

* $O$ cuidado é um fenômeno universal, e as formas de manifestação variam dentre os diversos grupos na relação tempo-espaço, alterando, na forma, a busca de seus atributos.

* $O$ cuidado, as manifestações, os processos, os valores e as crenças de enfermagem transcultural precisam ser explicados de maneira sistemática e científica com bases humanísticas.

* O cuidado de enfermagem terapêutico ou eficaz é, na maioria das vezes culturalmente determinado e embasado e pode ser culturalmente validado.

* As culturas têm seu modo peculiar do comportamento relativo ao cuidado, que é geralmente conhecido pelos integrantes da própria cultura, mas freqüentemente desconhecido por enfemeiras com bagagem cultural diferente.

* A essência da enfermagem é o cuidado; a essência da enfermagem transcultural é o cuidado a indivíduos de diversas heranças culturais.

* Os processos, as funções e atividades de enfermagem transcultural variam de acordo com a estrutura social e o sistema cultural e, em relação à sua história cultural, com seus contatos e sua aculturação. 
* As formas simbólicas do cuidado de enfermagem, e seu respectivo significado estāo intimamente relacionados às normas e crenças culturais que demandam estudo sistemático e representam modalidades importantes na compreensão e ajuda a determinados grupos.

Segundo LEININGER (1981) o comportamento e as práticas referentes ao cuidado são o que distingue a enfermagem de outras disciplinas e quatro são as razões para isto:

1. O construto do cuidado é essencial para o crescimento, o desenvolvimento e a sobrevivência humanas.

2. A finalidade é explicar e compreender o papel daquele que cuida e daquele que recebe o cuidado.

3. A preservação e manutenção do cuidado como um atributo humano é essencial para a sobrevivência dos seres humanos e das culturas através dos tempos.

4. A enfermagem é uma profissão que nunca estudou sistematicamente o cuidar e sua relação com o cuidado de enfermagem.

A autora considera o cuidado como o ato mais específico e poderoso para a enfermagem, mas que precisa ser documentado, compreendido e utilizado de forma terapêutica.

\section{A ENFERMAGEM TRANSCULTURAL E A PESQUISA}

Para LEININGER (1985 b) a teoria transcultural da diversidade e universalidade do cuidado é capaz de predizer e explicar os padrões de "cuidado humano" ("caring") das diversas culturas e as práticas do cuidado de enfermagem, bem como os fatores que o influenciam. Desta forma, propôs o modelo que denominou "Sunrise Model", simbolizado pelo nascer do sol, no sentido de auxiliar a análise do significado do cuidado para as diversas culturas (ANEXO I)

Este modelo considera a operacionalizaçāo de teoria e pesquisa e orienta o estudo da diversidade e universalidade do ato de cuidar. Através dele o pesquisador determina a abrangência e a profundidade do estudo. Tem sido utilizado por pesquisadores e combina teoria e método de pesquisa e distingue níveis de abstração e análise, assim como a abordagem metodológica na geraçào de conhecimento básico e aplicado.

A porção superior do círculo mostra os componentes interdependentes da estrutura social e dos fatores da visão do mundo que influenciam o cuidado e a saúde por meio da linguagem e do contexto ambiental. Estes fatores influenciam o sistema de saúde, compostos pelo sistema popular, profissional e o de enfermagem que se encontram na parte inferior do modelo. As porçōes superiores e inferiores descrevem um sol completo que corresponde ao universo; este precisa ser explorado pelas enfermeiras para que conheçam o cuidado humano e sua relação com a saúde.

À esquerda do diagrama estão dispostos os diversos níveis de abstração e análise do cuidado: macro, médio e micro referem-se à abrangência do estudo do cuidado. Níveis de abstração e análise são classificados em I, II, III, IV, correspondendo o nível I ao de maior abstração e o nível IV ao de menor. 
O nível I engloba o sistema social e a percepção do mundo sob três perspectivas: micro - estudos de pequena escala, ou seja, indivíduos dentro de determinada cultura; média - estudos em escala um pouco mais ampla de fatores complexos, numa cultura específica; macro - estudos em larga escala de várias culturas. Os dados incluem o significado, os atributos e a natureza do cuidado.

No nível II, são estudados o cuidado e a saúde, e incluem os indivíduos, famílias e culturas no contexto de um sistema de saúde, em busca de seus significados e de suas expressões.

No nível III são estudados os sistemas profissional e popular, na busca de características e aspectos específicos de cada sistema, com a finalidade de serem determinadas as áreas de semelhança e diferença.

O nível IV é utilizado para que seja desenvolvido um tipo de cuidado de enfermagem congruente com as culturas e por estas valorizado.

O modelo incorpora as idéias apresentadas no ANEXO II. Para conceituar o processo de pesquisa, o pesquisador precisa considerar os diferentes níveis de investigação e de teoria capazes de gerar conhecimento. $O$ conhecimento destes diversos níveis e abstração teórica clarifica os objetivos do estudo e a sua duração.

Ao lado direito do modelo está especificado o conhecimento que pode ser básico ou aplicado a situações práticas referentes ao cuidado universal e específico, gerado das teorias e pesquisas.

A autora considera o conhecimento básico e o aplicado como duas fases da geração e operacionalização do conhecimento específico da enfermagem. Desta forma, a enfermagem é considerada um campo de estudo básico com aplicação deste conhecimento em situações de enfermagem, contexto e intervenções. Sem o conhecimento científico básico e humanístico a enfermagem não se pode estabelecer como profissão. As duas fases para operacionalização do conhecimento da pesquisa em enfermagem estão sumarizadas no ANEXO III.

LEININGER (1978) afirma que sua teoria está embasada na crença de que as práticas do cuidado transcultural da enfermagem devem ser derivadas de estudo criterioso de crenças, valores e comportamentos de cuidado de diversos grupos culturais. $O$ produto destes estudos ajudará a formar profissionais de saúde e de enfermagem capazes de identificar e implementar o cuidado não apenas específico em determinada cultura como, também, de caráter universal.

A fim de atender às necessidades de indivíduos e grupos, a autora sugere a utilização de método derivado da etnografia, que denominou etno-enfermagem, para conhecer a forma como a cultura percebe, conhece e pratica o cuidado ou as atividades de cuidado de enfermagem; considera que a forma específica pela qual a cultura visualiza, conhece e experimenta o cuidado seja determinante no planejamento e implementação da assistência de enfermagem.

Outro ponto importante ressaltado pela mesma é o de se testar a validade da teoria geral da enfermagem transcultural; à medida que as enfermeiras se tornam capazes de predizer o comportamento tanto cultural como do cuidado de enfermagem mais confiáveis, tornar-se-ão os princípios, generalizaçōes e leis da enfermagem, possibilitando-lhes controlar ou regular suas intervençōes. 


\section{CONSIDERAÇÕES FINAIS}

A enfermagem transcultural é uma área de estudo estimulante e atraente, pois seus resultados contribuem para o desenvolvimento do saber de enfermagem que não se limita ao nível local; ao contrário, reflete-se no aperfeiçoamento desta profissão a nível mundial, pois é como se colegas de várias partes do mundo se aliassem em busca do conhecimento para provisão de cuidado culturalmente universal e/ou específico, ou seja, definam o fenômeno do cuidado para determinada cultura.

Encontramo-nos em tempo de participar deste avanço na enfermagem que, no futuro, tende a ser matéria já incorporada nos currículos das escolas de enfermagem e, portanto, no corpo de conhecimentos de enfermeiras de todo o mundo.

No Brasil, caracterizado por uma multiplicidade cultural determinada por sua própria história, tal estudo torna-se ainda mais fascinante, pela diversidade de crenças e de valores, referentes aos aspectos de saúde e, portanto expectativas das mais diversas com relação à qualidade e efetividade do cuidado de enfermagem.

Concomitante ao fascínio que seu estudo provoca, o assunto traz consigo a responsabilidade, principalmente das escolas de enfermagem, de incluírem em seu currículo uma parte voltada para o estudo da enfermagem transcultural, objetivando, além das já mencionadas vantagens, ampliar nossas perspectivas e nos auxiliar na visualização das idéias atuais acerca da saúde sob uma nova luz.

As noções de saúde e doença são fortemente influenciadas pelo contexto natural em que elas ocorrem, e variam de uma cultura para outra, possuindo, portanto, uma natureza subjetiva que precisa ser estudada em profundidade. Assim, pretendemos, com este artigo, facilitar a compreensão do assunto para aqueles que se iniciam no seu estudo e estimular novos colegas a se integrarem por este campo promissor da enfermagem; a sua colaboração será essencial para o pleno desenvolvimento da enfermagem transcultural entre nós.

GUALDA, D.M.R.; HOGA. L.A.K. Study of Leininger's transcultural care theory. Rev. Esc. Enf. USP, v. 26, n. 1, p. 75-86, mar. 1992.

The authors make a short review of the development of Transcultural Nursing, present several major concepts and definitions as well as some major assumptions of this theory. Some considerations are made on the "Sunrise" Theoretical Conceptual Model of Transcultural Care Diversity and Universality, developed and used by Leininger since 1965 to the present.

UNITERMS: Theory of nursing. Transcultural nursing.

\section{REFERÊNCIAS BIBLIOGRÁFICAS}

LEININGER, M.M. Caring: an essential human need. Thorofare, Charles B. Slak, 1981, cap. 1, p. 3-15: The phenomenon of caring: importance, research questions and theoretical considerations.

LEININGER, M.M. Qualitative research methods in nursing. 3. ed. Detroit, Grune \& Stratton, 1985. cap. 3, p. 33-71: Ethnograph and ethnonursing. (a). 
LEININGER, M.M. Transcultural care diversity ande universality: a theory of nursing. Nurs. Health Care, v. 6, n. 4, p. 209-12, 1985 (b).

LEININGER, M.M. Transcultural nursing; quo vadis (where goeth the field)? In: ANNUAL TRANSCULTURAL NURSING CONFERENCE, 11., Memphis, 1986. Proceedings. Memphis, Transcultural Nursing Society - 1986. p. 1-15.

LEININGER, M.M. Transcultural nursing: concepts, theories and practice. New York, John Wileys \& Sons, 1978. cap. 17, p. 31-51: Transcultural nursing theories and research approach.

MEAD, M. Understanding cultural patterns. Nurs. Outlook, v. 4, n. 5, p. 260-1, 1956. 


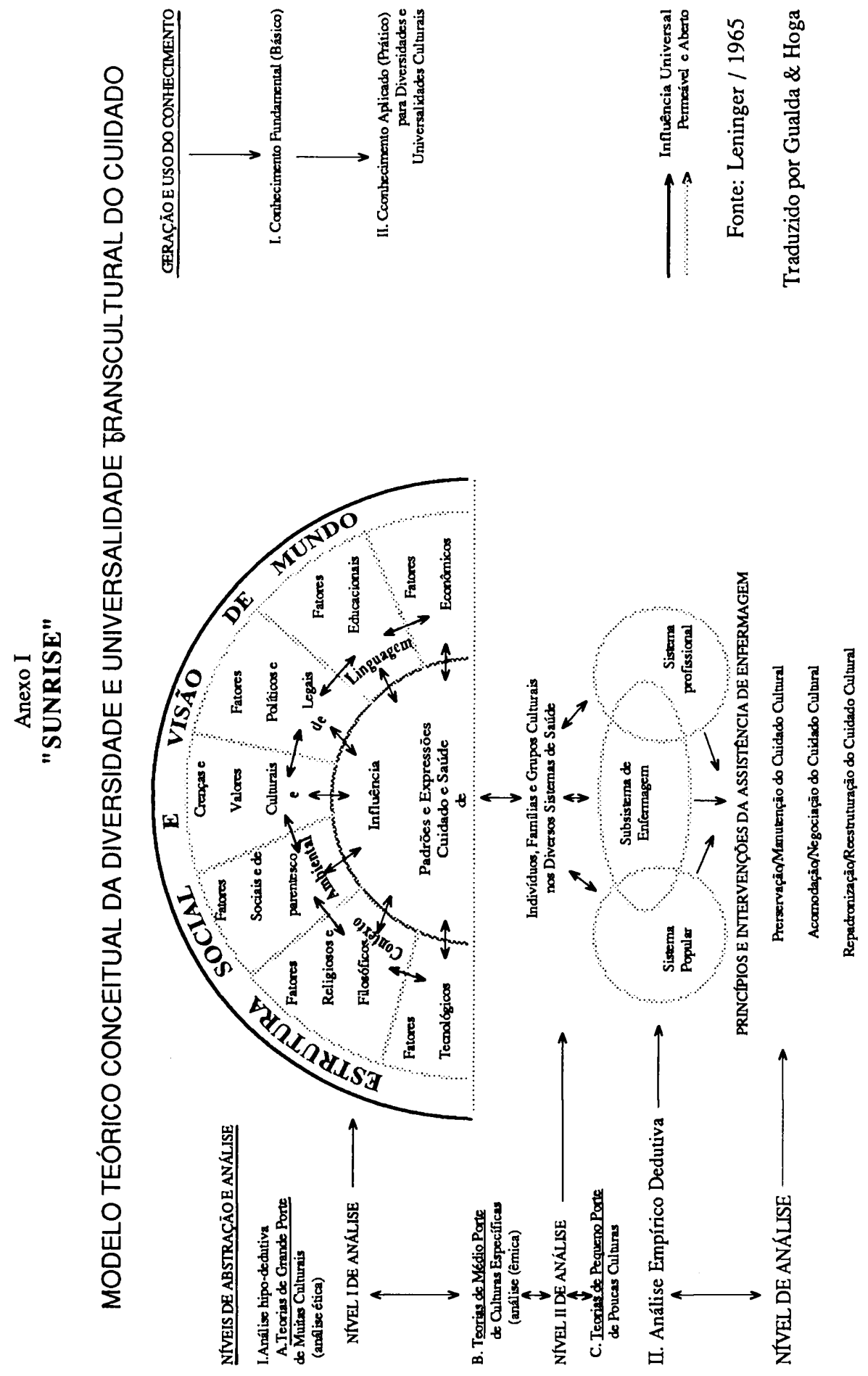




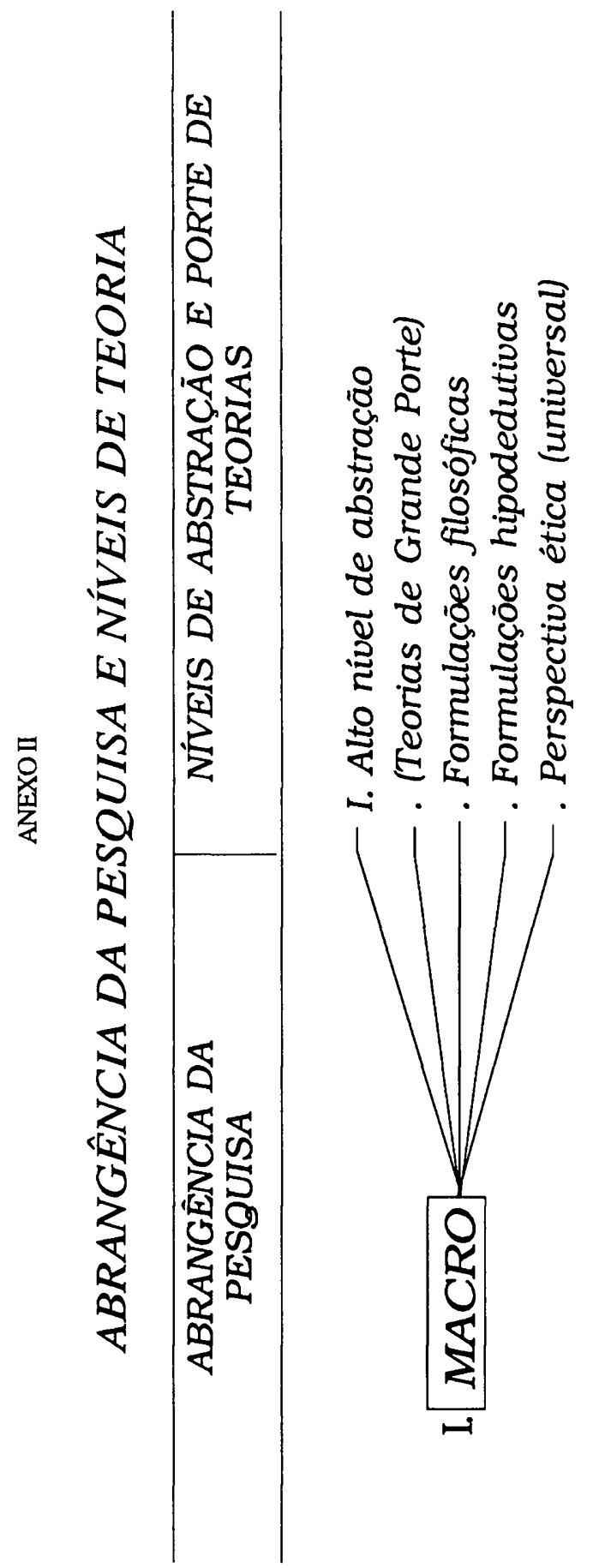

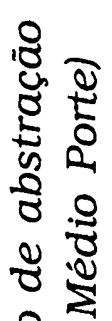

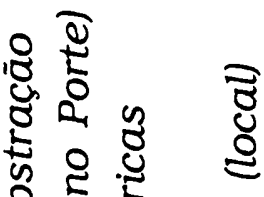

वิ

ป ठ

ชัช

ह

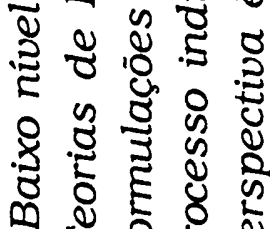

$\therefore$ E L 2
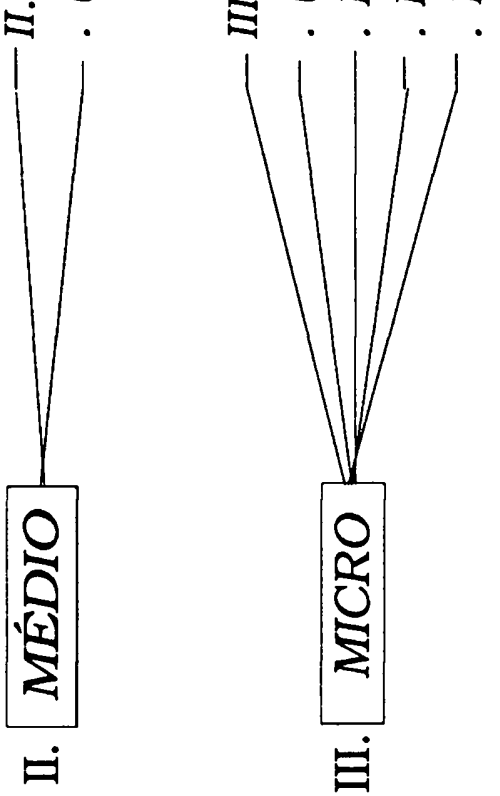


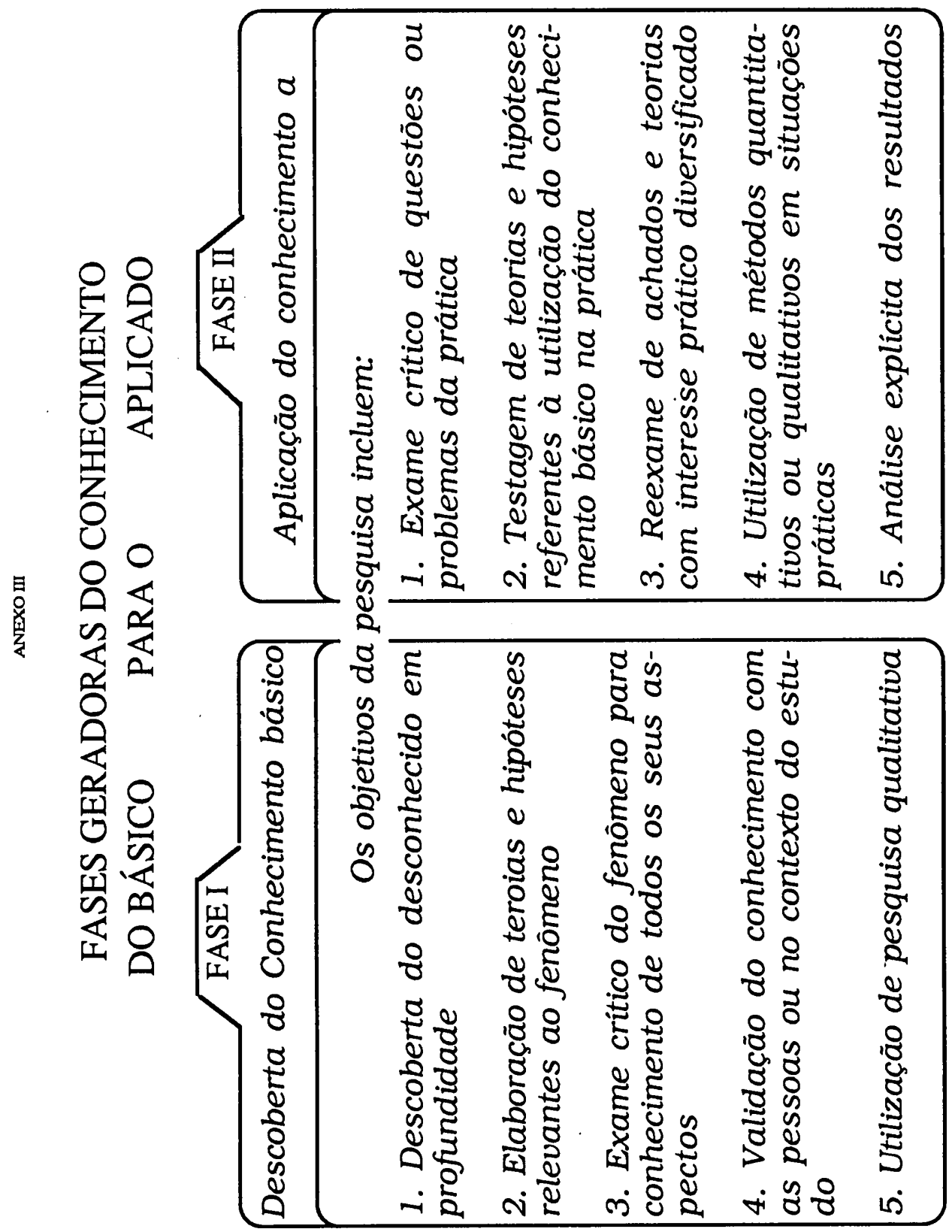

